\title{
Experimental Investigation on Tensile Properties of Carbon Fabric-Glass Fabric-Kevlar Fabric-Epoxy Hybrid Composite Laminates
}

\author{
Samer Al Khaddour ${ }^{1}$, Mohamad Barkat Ibrahim ${ }^{2 *}$ \\ ${ }^{1}$ Institute of Materials Science and Engineering, Brno University of Technology, 2896/2, Brno 61669, Czechia \\ ${ }^{2}$ Department of Applied Physics, Higher Institute for Applied Sciences and Technology, Damascus PO Box 31983, the Syrian \\ Arab Republic
}

Corresponding Author Email: mohammad.ibrahim@hiast.edu.sy

https://doi.org/10.18280/rcma.310305

Received: 28 January 2021

Accepted: 15 May 2021

\section{Keywords:}

carbon fabric, glass fabric, Kevlar fabric, epoxy resin, hybrid composites, tensile test

\begin{abstract}
In this paper, composite and hybrid composite materials were prepared using the hand lay-up method, with carbon, glass, and Kevlar fabrics as the reinforcing materials and epoxy as a matrix. The tensile test was performed to determine the optimal ratio of epoxy resin in carbon fabric/epoxy, glass fabric/epoxy, and Kevlar fabric/epoxy composites in terms of tensile properties. It was found that the optimal ratio of epoxy in terms of tensile properties to impregnate the used Kevlar fabric, glass fabric, and carbon fabric was around $45 \% \mathrm{wt}, 3 \% \mathrm{wt}$, and $30 \% \mathrm{wt}$, respectively. The effect of fabric content and stacking sequences, with a fixed epoxy content, on the hybrid composites' tensile properties were also investigated. The tensile properties of the prepared composites were compared to determine the most favorable preparation conditions for obtaining a hybrid laminate that has high tensile properties and is suitable for a wide range of applications at a low cost.
\end{abstract}

\section{INTRODUCTION}

Polymer matrix composite materials are used in many applications due to their numerous excellent mechanical properties as well their lightweights [1]. These composite materials have been heavily involved in the automobile, aircraft, tire reinforcement, sports industries, moreover the military industries $[1,2]$. The properties of polymer matrix composite materials vary widely according to the type of reinforcement material, which leads to different potential applications. Fiberglass reinforced polymer FGRP composites have a low cost compared to carbon or aramid fiber-reinforced polymer composites, but glass fibers have high density and lower mechanical properties than carbon fibers or aramid fibers [3]. Whereas, Carbon Fibers Reinforced Polymer composites are used for important applications such as warplanes due to their low density, high mechanical properties, and high-temperature resistance [4]. aramid-reinforced polymer composites are used in some parts of warplanes and bulletproof armors due to their low density, high mechanical properties, and their high ability to absorb and dissipate energy [5].

Several studies aimed to prepare and test inter-ply hybrid composite materials by using two different types of fabrics [68]. Fabric layers could be stacked above each other Symmetrically or Asymmetrically to get new mechanical properties a low cost. Fabric layers could be stacked above each other Symmetrically or Asymmetrically to get composite materials that have new mechanical properties at a low cost [8].

Badie et al. [9] investigated the effect of carbon and glass fibers orientation angles and stacking sequence in hybrid Carbon-Glass-Epoxy composites on the natural frequency, torsional stiffness, fatigue life, and buckling strength of composite tubes to use as an automotive drive shaft. According to finite element analysis, it was found that decreasing fiber orientation angles increased the natural frequency. Experimentally, higher torsional stiffness and higher load carrying capacity were found when fiber orientation angles of composite tubes were $\pm 45^{\circ}$. Jagannatha and Harish [10] prepared interply hybrid composites using glass and carbon fabrics and epoxy by vacuum bagging method. They investigated microhardness and tensile properties of the prepared composites, it was found that microhardness of the hybrid composites increases slightly when carbon fibers ratio increases, while the tensile properties are significantly improved by increasing carbon fibers ratio. Ibrahim et al. investigated stacking sequences of E-glass fabric and treated Kevlar-49 fabric in the hybrid Kevlar-Glass-Epoxy composites.

It was found that the asymmetric hybrid Kevlar-Glass-An epoxy composite that contains one treated Kevlar-49 layer and two E-glass layers has the highest Elastic modulus among the prepared hybrid composites [2]. Abasi et al. investigated the impact, hardness, and bending properties of epoxy composite reinforced by carbon and Kevlar short fibers. It was found that adding Kevlar fibers to short carbon fiber/epoxy composite improves the impact and bending properties, but the hardness decreases [11]. Randjbaran et al. [12] prepared interply hybrid composite laminates using glass, carbon, and Kevlar fabrics as reinforcing materials and epoxy as a matrix. They investigated the stacking sequences of five layers on ballistic energy absorption by employing the high-velocity ballistic impact test It was found that using carbon and glass layers in the middle of the composite is more efficient while using the carbon layer 
as the last layer decreases the ballistic energy absorption.

This work aims to prepare a three-layer laminated composite: Kevlar-Epoxy, Glass-Epoxy, and Carbon-Epoxy and to investigate their tensile properties to determine the best epoxy ratio within each composite. Then, the stacking sequences of Glass, Kevlar, and Carbon fabrics in the hybrid composites were investigated. To the best of the authors' knowledge, there is no previous study involving the preparation and tensile testing of a hybrid composite material containing Kevlar layer, carbon layer, and glass layer in the same hybrid composite material. So, this research is concerned with studying the tensile properties of several composite materials to obtain hybrid composite materials with high mechanical properties.

\section{MATERIALS AND METHODS}

\subsection{Materials}

Plain weave carbon fabric (fabric thickness $0.32 \mathrm{~mm}$ and surface density $200 \mathrm{~g} / \mathrm{m}^{2}$ ) and plain weave E-glass fabric (fabric thickness $0.37 \mathrm{~mm}$ and surface density $300 \mathrm{~g} / \mathrm{m}^{2}$ ) were purchased from Composites PLAZA

Plain weave Kevlar-49 fabric (fabric thickness $0.55 \mathrm{~mm}$ and surface density $400 \mathrm{~g} / \mathrm{m}^{2}$ ) was supplied from DuPont.

Araldite ${ }^{\circledR}$ LY 5052 Epoxy resin and Aradur ${ }^{\circledR} 5052$ hardener were purchased from Huntsman.

\subsection{Preparation of composites and specimens}

Epoxy specimens were prepared by mixing the epoxy resin with the curing agent at a specific ratio according to the datasheet [13]. To remove the air bubbles from the mixture, it was ultrasonicated using an ultrasonic water bath (BINDER). Then, the mixture was cast in Teflon molds immediately [2, 14]. After 24 hours, specimens were heat-treated for 5 hours at $60^{\circ} \mathrm{C}$ to complete epoxy hardening $[2,14]$. Finally, we get tensile specimens of epoxy designated by Ep.

All three-layer fabric-epoxy composites were prepared using the same method depending on our previous studies [2, 14]. Three fabric layers with $(12 \times 12) \mathrm{cm}^{2}$ dimensions were cut. This is followed by impregnating the layers with an appropriate amount of epoxy. We used an anti-bubble roller to remove air bubbles from each impregnated layer. Then, the three layers were placed above each other inside an appropriate mold for 24 hours under slight compression. Heat treatment was performed on the produced composite laminates for 5 hours at $60^{\circ} \mathrm{C}$. Finally, the jigsaw (MAKITA) was used to cut five tensile specimens from each composite laminate [2, 14]. Table 1 illustrates the codes of composite materials.

Table 1. Codes of composites

\begin{tabular}{cc}
\hline Carbon-Epoxy (wt) \% & 3C-Ep \% \\
\hline Kevlar-Epoxy (wt) $\%$ & 3K-Ep \% \\
\hline Glass-Epoxy (wt) $\%$ & 3 G-Ep \% \\
\hline
\end{tabular}

Hybrid composite laminates were symbolized according to the fabric stacking sequences over each other. For example, the hybrid composite laminate Carbon-Glass-Carbon-Epoxy $50 \%$ was symbolized as C-G-C-Ep50\%. Dimensions of the prepared composites were $(120 \mathrm{~mm} \times 120 \mathrm{~mm} \times d \mathrm{~mm})$ where $d$ is the thickness of composites. It is well known that Carbon-
Epoxy composites have high tensile properties and low density [4] and Kevlar-Epoxy composites have very good tensile properties, low density, and high impact resistance [2]. While Glass-Epoxy composites have good tensile properties, low density, and low cost [2]. Figure 1 shows the preparation method of the composites' specimens.

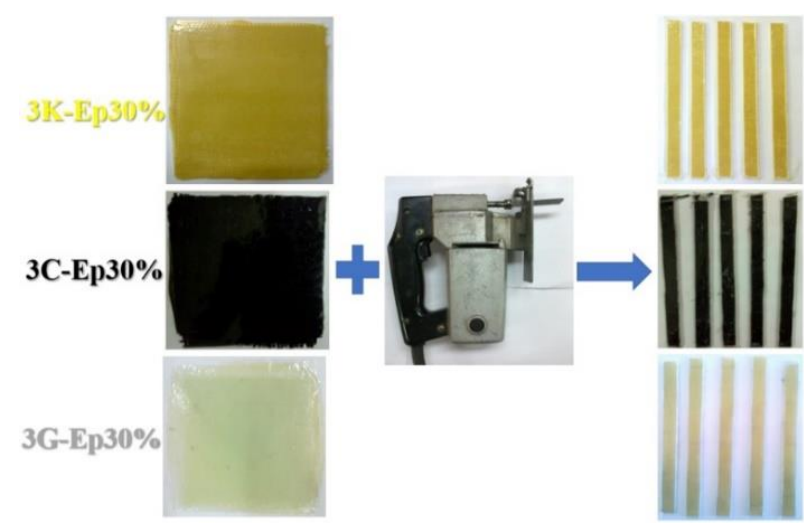

Figure 1. Preparation of tensile specimens

\subsection{Mechanical characterization}

Specimens' tensile properties were measured using a WDW-50 universal tester (Load resolution 1/300000, resolution of deformation $0.04 \mu \mathrm{m}$ ) as illustrated in Figure 2.

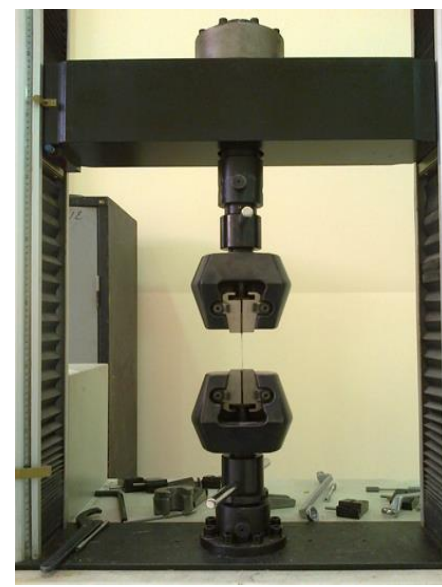

Figure 2. Tensile testing machine

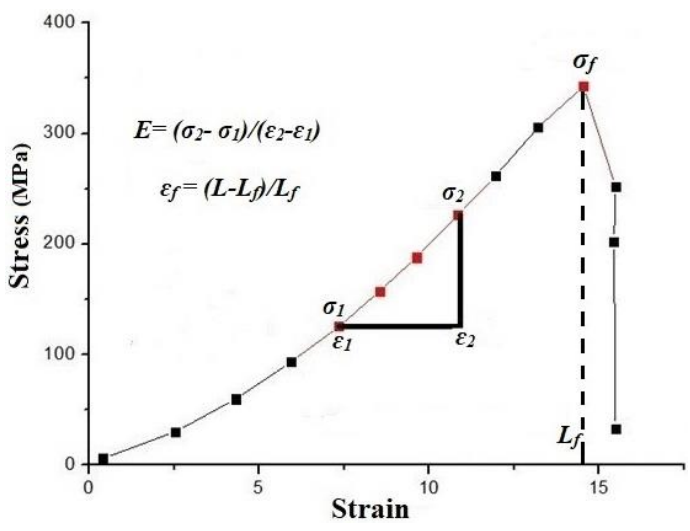

Figure 3. Typical tensile stress-strain diagram

The tensile test was performed according to the ASTM D3039 standard [15]. Dimensions of the rectangular tensile 
specimens were $(60 \mathrm{~mm} \times 10 \mathrm{~mm} \times d \mathrm{~mm})$ where $d$ is the thickness of composites. The average values and the standard deviations of tensile properties were calculated by testing five specimens of each laminate with a load speed of $2 \mathrm{~mm} / \mathrm{min}$. Depending on the stress-strain diagrams, we calculated the elastic modulus (Young's modulus) $E(\mathrm{MPa})$, tensile stress at break $\sigma_{f}(\mathrm{MPa})$, and fracture strain (tensile strain at break) $\varepsilon_{f}$ of each specimen as shown in Figure 3.

\section{RESULTS AND DISCUSSION}

Table 2 shows the Tensile test results of non-hybrid and hybrid composites that contain only two fabric types.

Table 2. Tensile test results of hybrid and non-hybrid composites

\begin{tabular}{|c|c|c|c|}
\hline $\begin{array}{c}\text { The } \\
\text { Composite }\end{array}$ & $\boldsymbol{E}(\mathrm{MPa})$ & $\sigma_{f}(\mathrm{MPa})$ & $\varepsilon_{f} \%$ \\
\hline Ep100\% & $2,831.34 \pm 48.72$ & $89.53 \pm 3.91$ & $\begin{array}{c}4.81 \pm \\
0.13\end{array}$ \\
\hline 3C-Ep30 \% & $\begin{array}{c}13,896.14 \pm \\
236.79\end{array}$ & $\begin{array}{c}589.58 \pm \\
12.86\end{array}$ & $\begin{array}{c}1.62 \pm \\
0.07\end{array}$ \\
\hline 3C-Ep45 \% & $\begin{array}{c}13,282.69 \pm \\
210.82\end{array}$ & $\begin{array}{c}471.32 \pm \\
18.37\end{array}$ & $\begin{array}{c}1.75 \pm \\
0.05\end{array}$ \\
\hline 3C-Ep60 \% & $\begin{array}{c}12,783.75 \pm \\
262.69\end{array}$ & $\begin{array}{c}408.93 \pm \\
13.94\end{array}$ & $\begin{array}{c}1.79 \pm \\
0.09\end{array}$ \\
\hline 3K-Еp30 \% & $\begin{array}{c}9,219.45 \pm \\
241.10\end{array}$ & $\begin{array}{c}426.43 \pm \\
26.37\end{array}$ & $\begin{array}{c}14.78 \pm \\
0.79\end{array}$ \\
\hline 3K-Ep45 \% & $\begin{array}{c}11,186.82 \pm \\
369.17\end{array}$ & $\begin{array}{c}549.48 \pm \\
28.00\end{array}$ & $\begin{array}{c}14.94 \pm \\
0.40\end{array}$ \\
\hline 3K-Ep60 \% & $\begin{array}{c}10,368.54 \pm \\
486.93\end{array}$ & $\begin{array}{c}437.20 \pm \\
15.73\end{array}$ & $\begin{array}{c}11.03 \pm \\
0.70\end{array}$ \\
\hline 3G-Ep30 \% & $\begin{array}{c}11,276.37 \pm \\
303.50\end{array}$ & $\begin{array}{c}403.75 \pm \\
9.96\end{array}$ & $\begin{array}{c}6.37 \pm \\
0.24\end{array}$ \\
\hline 3G-Ep45 \% & $\begin{array}{c}9,893.50 \pm \\
215.67\end{array}$ & $\begin{array}{c}326.53 \pm \\
11.22\end{array}$ & $\begin{array}{c}5.80 \pm \\
0.27\end{array}$ \\
\hline 3G-Ep60 \% & $\begin{array}{c}9,183.94 \pm \\
280.71\end{array}$ & $\begin{array}{c}310.40 \pm \\
14.90\end{array}$ & $\begin{array}{c}5.22 \pm \\
0.09\end{array}$ \\
\hline $\begin{array}{l}\text { C-C-K- } \\
\text { Ep30 \% }\end{array}$ & $\begin{array}{c}12,927.85 \pm \\
327.82\end{array}$ & $\begin{array}{c}514.86 \pm \\
12.97\end{array}$ & $\begin{array}{c}5.81 \pm \\
0.15\end{array}$ \\
\hline C-K-C- & $12,384.92 \pm$ & $499.18 \pm$ & $5.07 \pm$ \\
\hline Ep30 \% & 220.65 & 10.79 & 0.22 \\
\hline $\begin{array}{l}\text { C-C-G- } \\
\text { Ep30\% }\end{array}$ & $\begin{array}{c}12,580.16 \pm \\
313.97\end{array}$ & $\begin{array}{c}507.38 \pm \\
11.59\end{array}$ & $\begin{array}{c}2.44 \pm \\
0.12\end{array}$ \\
\hline C-G-C- & $12,968.61 \pm$ & $521.40 \pm$ & $2.51 \pm$ \\
\hline Ep30\% & 364.88 & 10.14 & 0.26 \\
\hline K-K-C- & $10,484.23 \pm$ & $482.72 \pm$ & $9.76 \pm$ \\
\hline Ep30 \% & 293.55 & 15.63 & 0.18 \\
\hline K-C-K- & $11,238.26 \pm$ & $497.31 \pm$ & $10.32 \pm$ \\
\hline Ep30 \% & 247.24 & 13.22 & 0.79 \\
\hline K-K-G- & $9,360.21 \pm$ & $418.24 \pm$ & $10.78 \pm$ \\
\hline Ep30 \% & 196.26 & 16.79 & 0.32 \\
\hline K-G-K- & $9,843.19 \pm$ & $422.76 \pm$ & $11.91 \pm$ \\
\hline Ep30 \% & 365.76 & 9.40 & 0.31 \\
\hline G-G-C- & $12,094.17 \pm$ & $470.74 \pm$ & $4.27 \pm$ \\
\hline Ep30 \% & 349.07 & 10.58 & 0.17 \\
\hline $\begin{array}{l}\text { G-C-G- } \\
\text { Ep30 \% }\end{array}$ & $\begin{array}{c}12,582.01 \pm \\
168.73\end{array}$ & $\begin{array}{c}459.42 \pm \\
8.48\end{array}$ & $\begin{array}{c}3.84 \pm \\
0.09\end{array}$ \\
\hline G-G-K- & $10,689.34 \pm$ & $412.08 \pm$ & $8.04 \pm$ \\
\hline Ep30 \% & 213.99 & 13.37 & 0.30 \\
\hline $\begin{array}{l}\text { G-K-G- } \\
\text { Ep30\% }\end{array}$ & $\begin{array}{c}10,083.28 \pm \\
353.07\end{array}$ & $\begin{array}{c}405.13 \pm \\
21.86\end{array}$ & $\begin{array}{c}7.69 \pm \\
0.16\end{array}$ \\
\hline
\end{tabular}

\subsection{Fabrics/epoxy non-hybrid composites}

Figure 4 presents the tensile properties of Fabrics/epoxy non-hybrid composites in terms of fibers ratio. Figures 4(a) \& 4(b) show that Elastic modulus and tensile stress of CarbonEpoxy and Glass-Epoxy composites increase when fibers ratio increase to $70 \%$, while Elastic modulus and tensile stress of Kevlar-Epoxy composite increase when Kevlar ratio increases to $55 \%$. Then, those tensile properties are reduced with more increase in the Kevlar ratio above $55 \%$. The low surface densities of the used carbon fabric $\left(200 \mathrm{~g} / \mathrm{m}^{2}\right)$ and glass fabric $\left(300 \mathrm{~g} / \mathrm{m}^{2}\right)$ explained why only $30 \%$ epoxy is the appropriate content as a matrix [2].

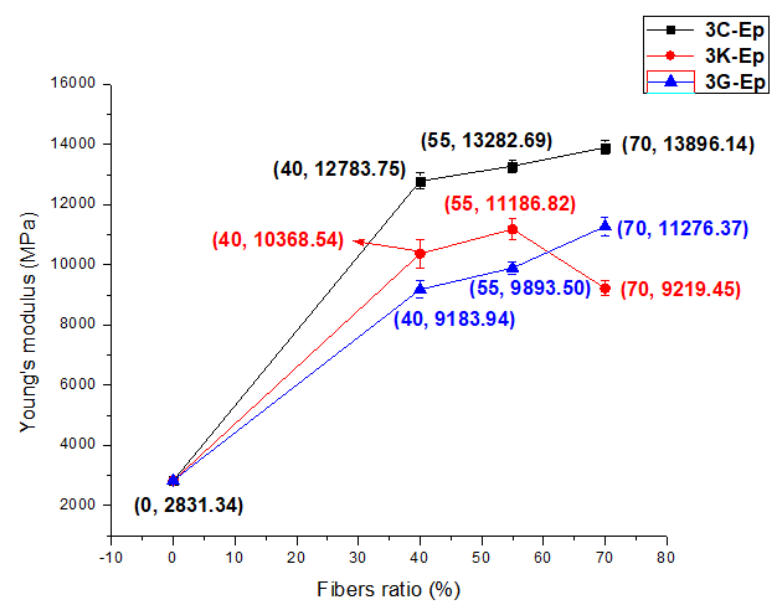

(a) Elastic modulus of fabric/epoxy composites

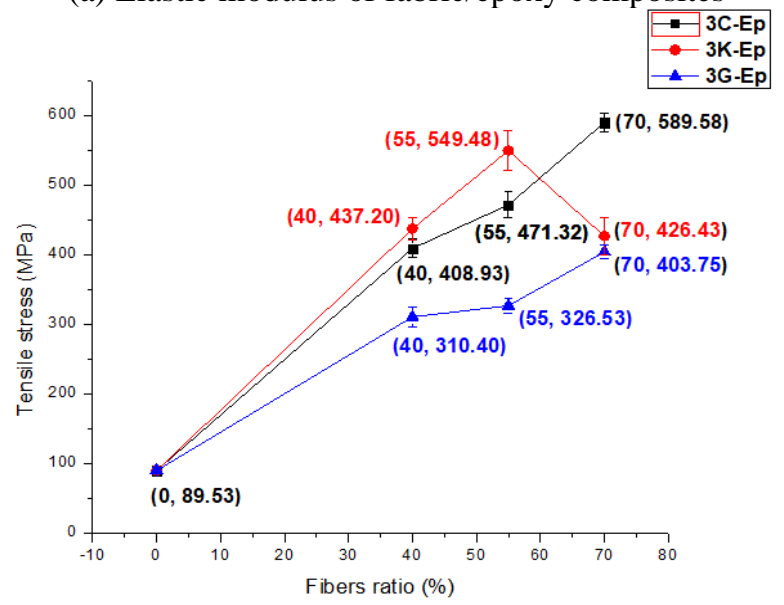

(b) Tensile stress of fabric/epoxy composites

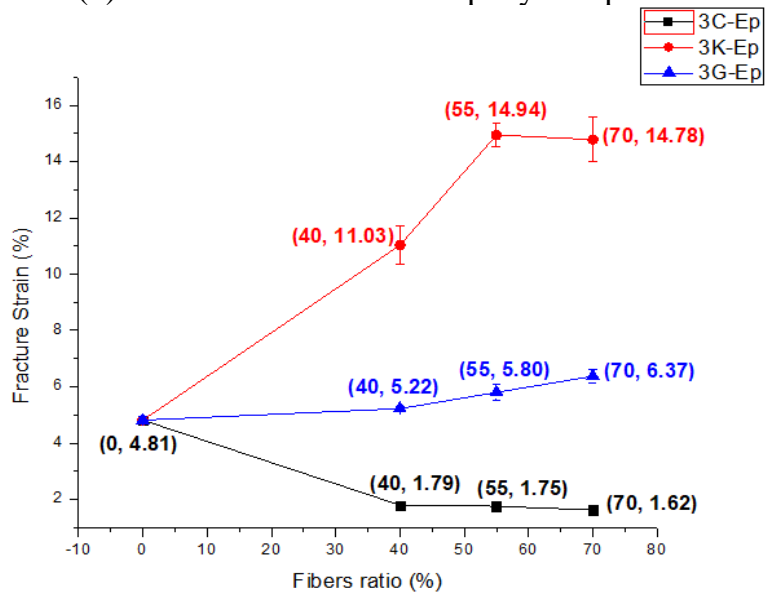

(c) Fracture strain of fabric/epoxy composites

Figure 4. Fabric-epoxy composites' tensile properties in terms of fibers ratio

As well, the low density and the high surface density of the used Kevlar fabric $\left(400 \mathrm{~g} / \mathrm{m}^{2}\right)$ explained why higher matrix content ( $45 \%$ epoxy) is the appropriate content as a matrix. At 
these proportions, a good transfer of stress between epoxy and fibers can be achieved without a shortage of the matrix material [2]. Figure 4 (c) shows that Kevlar-epoxy composites are more elastic than all other composites because Kevlar fibers are more elastic than glass and carbon fibers [2]. We also notice that strain at break values increases slightly for glass-epoxy composites when the glass ratio increases, while strain at break values decreases slightly for carbon-epoxy composites when carbon ratio increases. That was attributed to the fact that glass fibers are slightly more elastic than epoxy, while the epoxy is more elastic than carbon fiber.

\subsection{Kevlar-Carbon-epoxy30\% hybrid composites}

Figure 5 presents the tensile properties of Kevlar-Carbonepoxy $30 \%$ hybrid composites in terms of carbon ratio and the stacking sequence of carbon laminates. Figures 5(a) \& 5(b) show that Elastic modulus and tensile stress increase when carbon fibers ratio increase and 3C-Ep30\% composite material have the higher elastic modulus and tensile strength. That was attributed to the higher tensile properties of carbon fibers compared to Kevlar fibers [16]. In addition, the used Carbon fabric is surface treated in the manufacturing company with silane coupling agent, which improves the chemical bonding between carbon fibers and epoxy. Figure 5(c) shows that strain at break values decrease significantly when carbon ratio increase. A slight effect of the stacking sequence on the tensile properties of Kevlar-Carbon-epoxy $30 \%$ was noticed. But we can observe that the tensile properties of K-K-C-Ep30\% and $\mathrm{C}-\mathrm{K}-\mathrm{C}-\mathrm{Ep} 30 \%$ are less than tensile properties of $\mathrm{K}-\mathrm{C}-\mathrm{K}-$ Ep30\% and C-C-K-Ep30\% respectively. This can be explained by the fact that the presence of the Kevlar layer in the middle of the composite material constitutes a weakness in the center of the composite material's body since the used ratio of epoxy (30\% by weight) is not sufficient to impregnate the high surface density Kevlar layer.

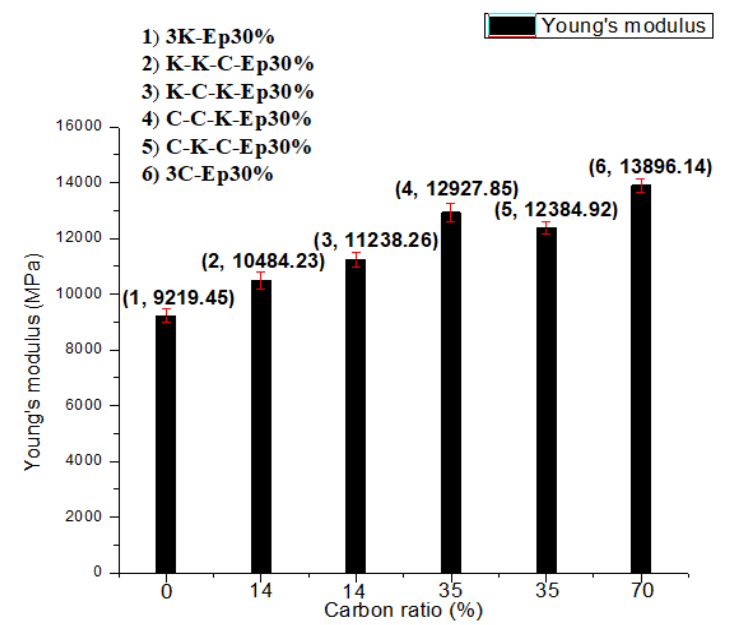

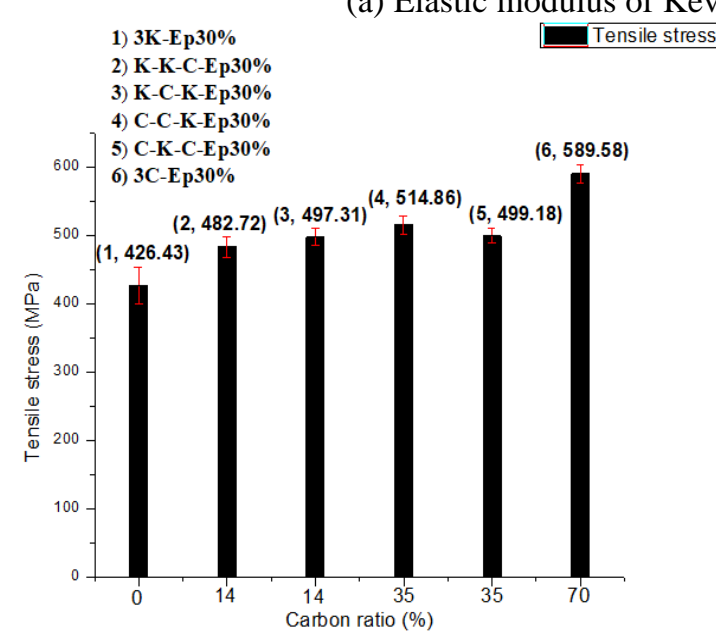

(b) Tensile stress of Kevlar-Carbon-epoxy composites

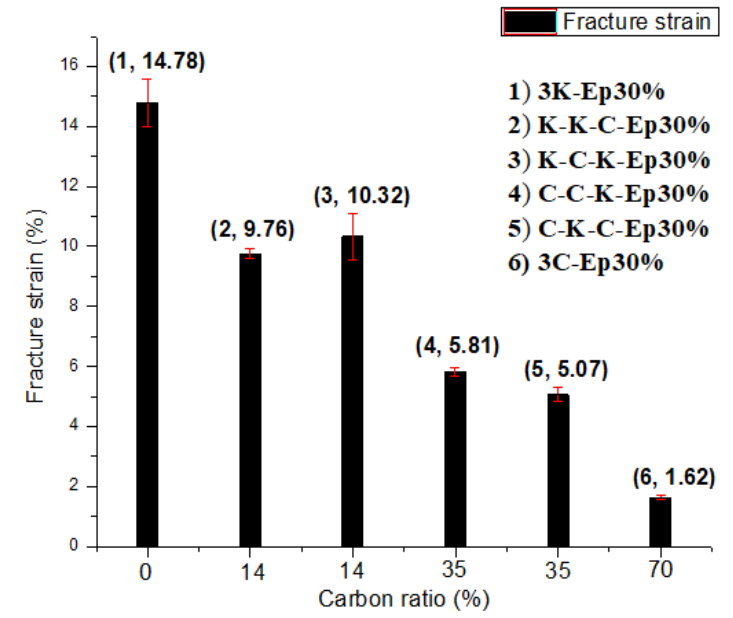

(c) Fracture strain of Kevlar-Carbon-epoxy composites

Figure 5. Kevlar-Carbon-Epoxy30\% composites' the tensile properties in terms of carbon ratio

\subsection{Glass-Carbon-epoxy30\% hybrid composites}

Figure 6 presents the tensile properties of Glass -Carbonepoxy $30 \%$ hybrid composites in terms of carbon ratio and the stacking sequence of carbon laminates. Figures $6(a) \& 6(b)$ show that Elastic modulus and tensile stress increase when carbon fibers ratio increase to get their highest values in the non-hybrid composite material C-Ep30\%, since carbon fibers have higher Elastic modulus and higher tensile stress than glass fibers. Figure 6(c) shows that strain at break values decreases significantly when the carbon ratio increase as carbon fibers are stiffer than glass fibers. No effect of the stacking sequence on tensile properties of Glass-Carbonepoxy30\% was noticed where the tensile properties differ between symmetric hybrid composite materials and their asymmetric counterparts within the standard deviation range of these properties' values and these results fit well with reference [17]. 

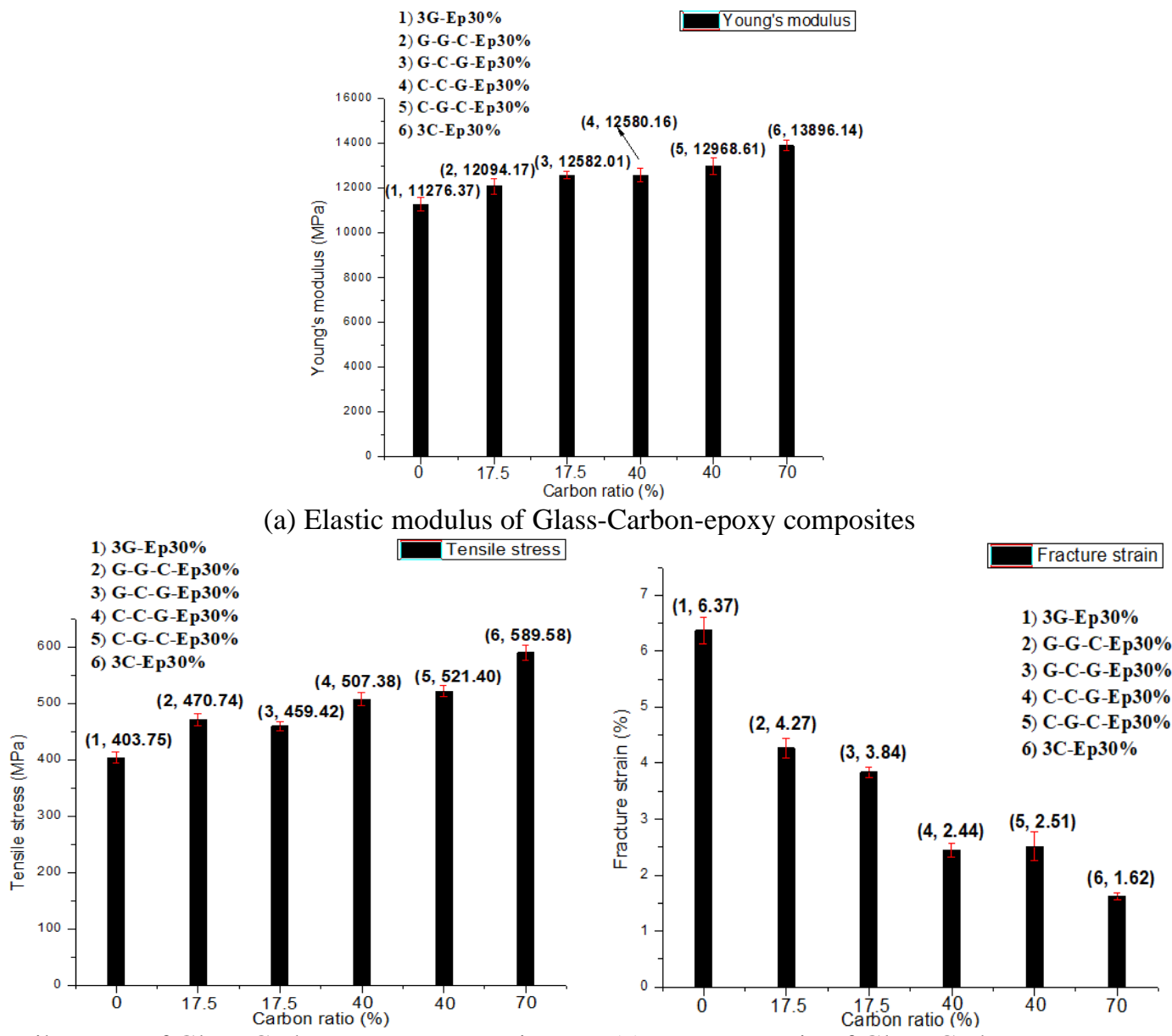

(b) Tensile stress of Glass-Carbon-epoxy composites

(c) Fracture strain of Glass-Carbon-epoxy composites

Figure 6. Glass-Carbon-Epoxy30\% composites' tensile properties in terms of carbon ratio

\subsection{Glass-Kevlar-epoxy30\% hybrid composites}

Figure 7 presents the tensile properties of Glass -Kevlarepoxy $30 \%$ hybrid composites in terms of Kevlar ratio and the stacking sequence of Kevlar layers. Figure 7(a) shows a gradual decrease in Elastic modulus values when Kevlar fibers ratio increase and Figure 7(b) shows a slight increase in tensile stress when Kevlar fibers ratio increase. Although the mechanical properties of Kevlar fibers are higher than those of glass fibers, the chemical inertness of Kevlar fibers means that the bonding between Kevlar and epoxy is weak. That leads to weak mechanical properties of Kevlar-epoxy composite [2, 18-20], and we use Kevlar-49 fabric as received. Studies have also shown that tensile stress values of Kevlar-49/epoxy composites were different from each other when these values were experimentally determined and calculated from the rule of mixture $[2,21]$.

The used glass fabric is surface treated in the manufacturing company with a specific silane coupling agent, which improves the chemical bonding between glass fibers and epoxy, and this improves the mechanical properties of glassepoxy composites significantly [22, 23]. Figure 7(c) shows that strain at break values significantly increased when the Kevlar ratio increase. This is due to the plastic nature of Kevlar, as Kevlar fibers deform and elongate during the tensile despite their weak bond with epoxy.

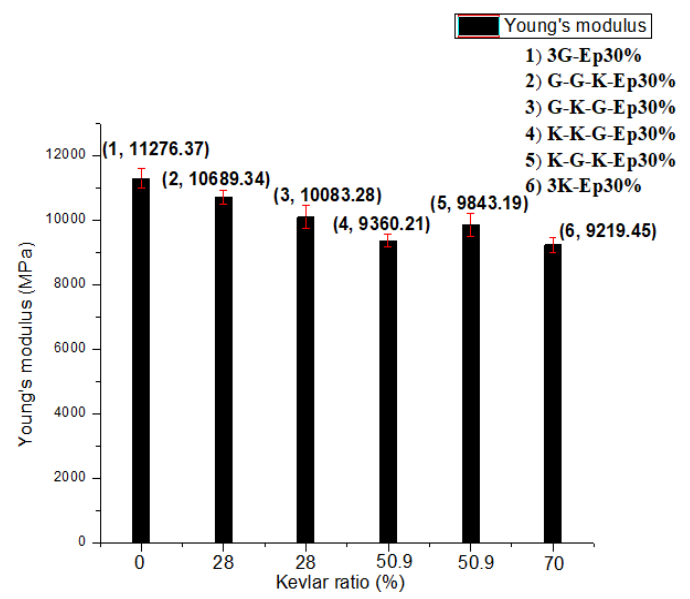

(a) Elastic modulus of Glass-Kevlar-epoxy composites 


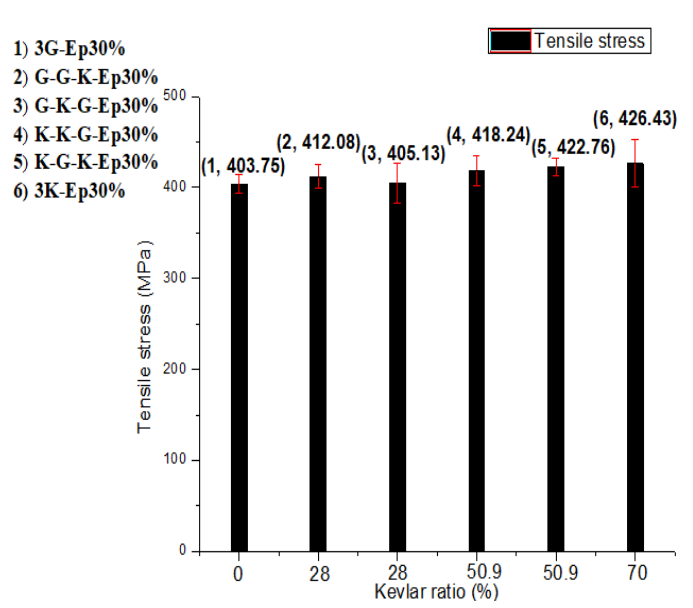

(b) Tensile stress of Glass-Kevlar-epoxy composites

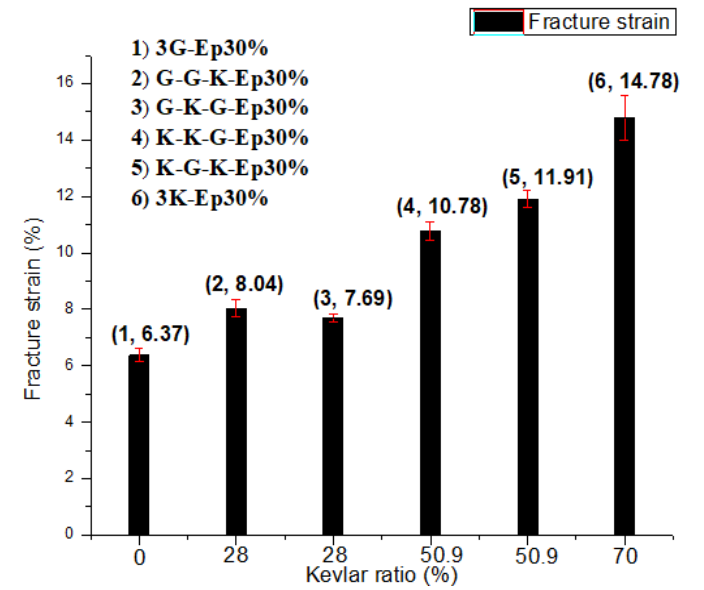

(c) Fracture strain of Glass-Kevlar-epoxy composites

Figure 7. Glass-Kevlar-Epoxy30\% composites' tensile properties in terms of Kevlar ratio

\subsection{Carbon-Glass-Kevlar-epoxy $30 \%$ hybrid composites}

Table 3 shows the Tensile test results of hybrid composites that contain three fabric types.

Table 3. Tensile results of hybrid composites that contain three fabrics types

\begin{tabular}{cccc}
\hline The & $E(\mathrm{MPa})$ & $\sigma_{f}(\mathrm{MPa})$ & $\varepsilon_{f} \%$ \\
\hline Composite & & $438.72 \pm$ & $10.22 \pm$ \\
C-K-G- & $11 \mathrm{~s}, 428.34 \pm$ & 11.20 & 0.27 \\
Ep30 \% & 239.99 & $462.09 \pm$ & $9.89 \pm$ \\
C-G-K- & $11,804.96 \pm$ & 8.80 & 0.24 \\
Ep30 \% & 237.54 & $497.84 \pm$ & $10.07 \pm$ \\
K-C-G- & $11,837.43 \pm$ & 10.09 & 0.31 \\
Ep30 \% & 212.49 & & \\
\hline
\end{tabular}

According to Table 3, strain at break values is very close to each other for the three composite materials, which means that there is no effect of the stacking sequences in these composites on strain at break. We also note the convergence of the Elastic modulus values with a slight decrease in the Elastic modulus value for the composite material C-K-G-Ep30\%. The same composite material also has the lowest tensile strength.

This can be explained by the presence of the Kevlar layer in the middle of the composite material constituting a weakness in the center of the composite material's body since the used ratio of epoxy ( $30 \%$ by weight) is not sufficient to impregnate the Kevlar layer. The K-C-G-Ep30\% composite material has the highest tensile strength, as placing the carbon layer that has the highest tensile stress in the middle of the composite material improves the tensile stress of the hybrid composite material.

\section{CONCLUSIONS}

In this work, several composite laminates were prepared, using Kevlar, glass, and carbon fabrics as reinforcing materials and epoxy as the matrix. The optimum ratio of epoxy in the non-hybrid composites was determined in terms of their tensile properties.

It was observed that increasing carbon layers in carbonKevlar-epoxy and carbon-glass-epoxy hybrid composites significantly improved the Elastic modulus and tensile stress and decreased fracture strain values. In comparison, a gradual decrease in Elastic modulus, an increase in the strain at break values, and the preservation of tensile stress values can be observed in glass-Kevlar-epoxy composites when the ratio of Kevlar fibers increases in these hybrid materials.

It was also found that the stacking sequences have no noticeable effect on the hybrid composite materials, except on those that contain a Kevlar layer in the middle, in which case the tensile properties decreased. New hybrid composite materials (consisting of a Kevlar layer, a glass layer, and a carbon layer in the same composite material) were also prepared and tested with variations in the stacking sequences. It was found that $\mathrm{K}-\mathrm{C}-\mathrm{G}-\mathrm{Ep} 30 \%$ composite material has high tensile stress that equals $497.84 \mathrm{MPa}$.

\section{REFERENCES}

[1] Agrawal, S., Singh, K.K., Sarkar, P.K. (2014). Impact damage on fibre-reinforced polymer matrix composite-a review. Journal of Composite Materials, 48(3): 317-332. https://doi.org/10.1177/0021998312472217

[2] Ibrahim, M.B., Habib, H.Y., Jabrah, R.M. (2020). Preparation of Kevlar-49 fabric/E-glass fabric/epoxy composite materials and characterization of their mechanical properties. Revue des Composites et des Matériaux Avancés-Journal of Composite and Advanced Materials, $\quad 30(3-4)$ : 133-141. https://doi.org/10.18280/rcma.303-403

[3] Sathishkumar, T.P., Satheeshkumar, S., Naveen, J. (2014). Glass fiber-reinforced polymer composites-A review. Journal of Reinforced Plastics and Composites, 33(13): $1258-1275$ https://doi.org/10.1177/0731684414530790

[4] Liu, Y., Zwingmann, B., Schlaich, M. (2015). Carbon fiber reinforced polymer for cable structures-A review. Polymers, 7(10): 2078-2099. https://doi.org/10.3390/polym7101501

[5] Singh, T.J., Samanta, S. (2015). Characterization of Kevlar fiber and its composites: A review. Materials Today: Proceedings, 2(4-5): 1381-1387. https://doi.org/10.1016/j.matpr.2015.07.057

[6] Pegoretti, A., Fabbri, E., Migliaresi, C., Pilati, F. (2004). Intraply and interply hybrid composites based on E-glass and poly (vinyl alcohol) woven fabrics: Tensile and impact properties. Polymer International, 53(9): 12901297. https://doi.org/10.1002/pi.1514 
[7] Uzay, Ç., Acer, D.C., Geren, N. (2017). Impact strength of interply and intraply hybrid laminates based on carbon-aramid/epoxy composites. European Mechanical Science, 3(1): 1-5. https://doi.org/10.26701/ems.384440

[8] Attia, M.A., Abd El-baky, M.A., Alshorbagy, A.E. (2017). Mechanical performance of intraply and interintraply hybrid composites based on e-glass and polypropylene unidirectional fibers. Journal of Composite Materials, 51(3): 381-394. https://doi.org/10.1177/0021998316644972

[9] Badie, M.A., Mahdi, E., Hamouda, A.M.S. (2011). An investigation into hybrid carbon/glass fiber reinforced epoxy composite automotive drive shaft. Materials \& Design, 32(3): 1485-1500. https://doi.org/10.1016/j.matdes.2010.08.042

[10] Jagannatha, T.D., Harish, G. (2015). Mechanical properties of carbon/glass fiber reinforced epoxy hybrid polymer composites. International Journal of Mechanical Engineering and Robotics Research, 4(2): 131-137.

[11] Abasi, F.O., Aabass, R.U. (2018). Thermo-mechanical behavior of epoxy composite reinforced by carbon and Kevlar fiber. In MATEC web of Conferences, 225: 1-8. https://doi.org/10.1051/matecconf/201822501022

[12] Randjbaran, E., Zahari, R., Abdul Jalil, N.A., Abang Abdul Majid, D.L. (2014). Hybrid composite laminates reinforced with Kevlar/carbon/glass woven fabrics for ballistic impact testing. The Scientific World Journal, 2014: 413753. https://doi.org/10.1155/2014/413753

[13] Araldite® LY 5052/Aradur® 5052 Technical data sheet. (2012). Cold curing epoxy system. www.huntsman.com, accessed on Jan.

[14] Ibrahim, M.B., Habib, H.Y., Jabrah, R.M. (2020). Preparation and mechanical characterisation of basalt fabric, epoxy, and silicon dioxide composite materials. The Scientific Journal of King Faisal University-Basic and Applied Sciences, 21(2): 167-171. https://doi.org/10.37575/b/sci/0007

[15] ASTM D 3039. Standard test method for tensile properties of polymer matrix composite materials. West Conshohocken, PA: ASTM D 3039, 2000, p. 10.

[16] Medeiros, R.J.D., Nóbrega, S.H.S.D., Aquino, E.M.F.D. (2019). Failure theories on carbon/Kevlar hybrid fabric based composite laminate: notch and anisotropy effects. Materials Research, 22(3): 1-11. https://doi.org/10.1590/1980-5373-mr-2018-0099

[17] Agarwal, G., Patnaik, A., Kumar Sharma, R., Agarwal, J. (2014). Effect of stacking sequence on physical, mechanical and tribological properties of glass-carbon

hybrid composites. Friction, 2(4): 354-364. https://doi.org/10.1007/s40544-014-0068-9

[18] Li, G., Zhang, C., Wang, Y., Li, P., Yu, Y.H., Jia, X.L, Liu, H.Y., Yang, X.P., Xue, Z.M., Ryu, S. (2008). Interface correlation and toughness matching of phosphoric acid functionalized Kevlar fiber and epoxy matrix for filament winding composites. Composites Science and Technology, 68(15-16): 3208-3214. https://doi.org/10.1016/j.compscitech.2008.08.006

[19] Zhao, J. (2013). Effect of surface treatment on the structure and properties of para-aramid fibers by phosphoric acid. Fibers and Polymers, 14(1): 59-64. https://doi.org/10.1007/s12221-013-0059-X

[20] Kong, H.J., Sun, H., Chai, J., Ding, H.Q., Ding, X.M., Qiao, M.M., Yu, M.H., Zhang, Y.F. (2019). Improvement of adhesion of Kevlar fabrics to epoxy by surface modification with acetic anhydride in supercritical carbon dioxide. Polymer Composites, 40(S1): E920-E927. https://doi.org/10.1002/pc.25100

[21] Mittelman, A., Roman, I. (1990). Tensile properties of real unidirectional Kevlar/epoxy composites. Composites, 21(1): 63-69. https://doi.org/10.1016/00104361(90)90099-I

[22] Hearle, J.W. (2001). High-Performance Fibres. Woodhead Publishing.

[23] Park, S.J., Jin, J.S. (2001). Effect of silane coupling agent on interphase and performance of glass fibers/unsaturated polyester composites. Journal of Colloid and Interface Science, 242(1): 174-179. https://doi.org/10.1006/jcis.2001.7788

\section{NOMENCLATURE}

d

E

\section{Greek symbols}

$\sigma_{f}$

$\varepsilon_{f}$

\section{Subscripts}

C

$\mathrm{G}$

$\mathrm{K}$

Ep
Thickness (mm)

Elastic modulus (MPa)

Tensile stress at break (MPa)

Fracture strain (dimensionless)
Carbon

Glass

Kevlar

Epoxy 